\title{
Cross-Cultural Knowledge Construction: A Case Study of a Mini Field Work in Breivang High School (Northern Norway)
}

\author{
Richard Atimniraye Nyelade, Dunfu Zhang \\ School of Sociology and Political Science, Shanghai University, Shanghai, China \\ Email: atimniraye2013@gmail.com
}

How to cite this paper: Nyelade, R. A., \& Zhang, D. F. (2020). Cross-Cultural Knowledge Construction: A Case Study of a Mini Field Work in Breivang High School (Northern Norway). Open Journal of Social Sciences, 8, 143-152.

https://doi.org/10.4236/jss.2020.84010

Received: March 11, 2020

Accepted: April 11, 2020

Published: April 14, 2020

Copyright $\odot 2020$ by author(s) and Scientific Research Publishing Inc. This work is licensed under the Creative Commons Attribution International License (CC BY 4.0).

http://creativecommons.org/licenses/by/4.0/

\begin{abstract}
Visual anthropology is a subfield of social anthropology which aims at getting insights into people's lives through interaction and collaboration between the researcher and the researched mediated by a camera. This study which is based on document analysis and a two-week fieldwork in a high school, tries to retrace the evolution of shared anthropology from the fore fathers to its current developments and implementations. First of all, the founding principles of anthropology contributed to the underestimation of the camera in scientific research. Then, in the 1950s, contrary to the reifying perspectives of the first anthropologists influenced by positivism and structuralism, Jean Rouch orients anthropology towards a new approach by introducing the concept of shared anthropology.
\end{abstract}

\section{Keywords}

Shared Anthropology, Knowledge Construction, Fieldwork, Camera, Native

\section{Introduction}

Visual anthropology is a subfield of social anthropology which aims at getting insights into people's lives through interaction and collaboration between the researcher and the researched mediated by a camera. Before being considered as a scientific discipline which is taught in many universities all over the world, visual ethnography went through different phases: from armchair anthropology to what is termed today as shared anthropology.

First of all, the founding principles of anthropology (Hockings, 1974) contributed to the underestimation of the camera in scientific research. In fact, since its academic emergence in the 1880s, anthropology was given the mission to 
study-the self-other relationship in other cultures (Augé, 1994). This was the time when some ethnologists were sent by colonial masters to indigenous communities in order to study their cultures and traditions prior to their colonization. On the other hand, other anthropologists were driven by the zeal of discovering the primitives, the-noble salvages and the desire of preserving their vanishing cultures in the face of industrialization, urbanization and recently, globalization, at that time,--ethnologists limited themselves to bringing indigenous people into their colonial residences to interview them (Dion, 2007). At the image of his settlers' colleagues, the ethnologist was considered as a superhuman, an enlightened who is observing the poor and powerless-exotic other, from a distance. This is why Jean Rouch considered the anthropological approach of that time as-the elder daughter of colonialism, a discipline reserved to those with power interrogating people without it" (cited by Ruby, 2000).

Besides, some social scientists were influenced by the model of natural sciences-physics, mathematics, chemistry, biology. Hence, they were convinced that they could gain an objective understanding of human behaviors and social facts. In anthropology specifically, Levi-Strauss (1976) and his structuralist followers made attempts to discover laws that could govern human customs as well as the hidden structures that could determine their thoughts and action.

In the 1950s, contrary to the reifying perspectives of the first anthropologists influenced by positivism and structuralism, Jean Rouch orients anthropology towards a new approach by introducing the concept of shared anthropology. Henceforth, the researcher and the researched are considered as collaborators and the subjectivity of the former is considered as an asset to gain more in depth in the process of knowledge production. Furthermore, the camera is considered as a third actor who intervenes in the interaction between the anthropologist and his informants. This innovative approach is defined by Rouch (2003) as an anthropological dialogue between people belonging to different cultures. During the two-week fieldwork my classmate and I had at Breivang high school, we tried to implement the notion of shared anthropology. This paper aims at relating the different processes we followed in order to gain an anthropological knowledge from our fieldwork thanks to the contributions of our informants, the camera and our involvement as researchers and researched. After a brief presentation of the fieldwork and, I will highlight progressively how I approached my informants, the interactions between me, my informants and the camera during the film period; and the transformation of the data in editing room thanks to the contribution of the audience.

\section{Background of the Study}

Following the agenda at the Master program in Visual Cultural Studies (VCS) at the University of Tromsø, a two-week fieldwork film has to be made by the students as part of their first year's training. Hence, the present mini fieldwork 
team fell in the realm of the project for the implementation of Restorative Justice in Norway.

Restorative justice is an approach to the notion of justice that focuses on the needs of the victims and the offenders, as well as the involved community, instead of satisfying abstract legal principles or punishing the offender. Victims take an active role in the process, while offenders are encouraged to take responsibility for their actions, "to repair the harm they have done by apologizing, returning stolen money, or community service". In addition, it provides help for the offender in order to avoid future offences. It is based on a justice theory that considers crime and wrongdoing to be an offence against an individual or community, rather than the state. Restorative justice that fosters dialogue between victim and offender shows the highest rates of victim satisfaction and offender accountability.

Known as a peaceful country, Norway wants to develop the culture of peace from the young ones. That's why since 2010, the government has introduced the Restorative Justice program. In Northern Norway, Breivang high school has been chosen among the first schools where the program has been introduced. After three years of existence, in 2013, the government has organized a big Symposium that has gathered teachers, educators, administrators and students from different high schools as well as from the University of Tromsø and the Red Cross. The goal of the Symposium was to assess the results so far obtained in the implementation of Restorative Justice in High Schools.

In the department of Visual Cultural Studies, 5 Teams have been made up in order to cover the event with a 15 minutes film and a fieldwork report. Different aspects of Restorative Justice have been assigned to each group varying from Street mediation to school mediation passing by social mediation. My classmate and I got the assignment of working on the impact of School Mediation at Breivang High School.

\section{Approaching My Informants}

For fear of pretending to get access to an objective knowledge as the first anthropologists did, I recognize that my approach to the informants was influenced by the anthropological theories I have learned so far and my African eye (to allude to Lisbeth Holtedahl's (1993) Nordic eye.

\subsection{Theoretical Assumptions}

When this theme was given to us, the first idea we had in mind was to follow the daily life of Håkon Pettersen, a social worker in the school. In fact, this idea stemmed from the trend observed in most ethnographic and anthropological films where the character driven approach is the prominent. That's why we decided to have as title of our mini fieldwork project: Håkon Pettersen: a dynamic social worker at the service of Breivang High School. So, during the first days of the fieldwork, I and my classmate were obsessed by the idea of placing Håkon at 
the center of everything. Lead by Erving Goffman's theory of actions, our aim was to film while performing his different tasks as a social worker and a Restorative Justice teacher.

However, the realities in the fieldwork brought some modifications to our initial perspective. Firstly, the first week when we landed at Breivang high school we were welcomed by Håkon Pettersen who introduced us to his colleagues. We started by filming a conference workshop and then a school mediation circle where Håkon himself was the main organizer. Everything started well as we planned in our project.

Yet, by the end of the day, we were disappointed and a bit worried when Håkon announced us that he was surprisingly called to leave his position as a social worker for another job. So, we could not have him available for our project anymore. We thought this would influence the progression of our project. We started to think to change our main character and follow a young girl student in the same school who seemed to be interested in talking on her experience with regards to school mediation. Contrary to some of her classmates who were self-conscious by the presence of the camera, she was the one who came and met us and said she wanted to be interviewed. But because of some ethical problems, we found we couldn't follow her specifically.

After a while, we thought maybe it could be an alternative to follow one of Håkon's close colleagues in case of his absence. However, some teachers were reluctant in front of the camera and some expressed openly their disapproval to be filmed. Stuck in this situation between the eventual transfer of Håkon and the reluctance of some potential informants, our chances of making an amazing fieldwork were becoming fewer as two days had already passed. But we didn't prepare any theory or hypothesis in case of the unavailability of our main informant. We took for granted his presence. From there, we understood that the fieldwork has some realities, or rules which can only be discovered on the course of action in the field. So, we had to be innovative and find a solution to continue with our work.

The whole second day could be wasted with almost nothing to do and no contact person with whom to communicate in order to get in touch with the students. Fortunately, there was a second meeting programmed that day in Sylvi's class. She was Håkon's colleague and seemed to be rather very excited at the idea of being filmed and interviewed. So, she helped us to be our first contact with the students and other colleagues. I will come later to the details and the continuation of our research from this first contact.

\subsection{Technical Approach: The Position of the Camera}

The camera played a tremendous role in this mini fieldwork. In order to better seize the natives' point of view (Boaz, 1989), (Manilowski, 1989), my classmate and I decided to try the two dominant approaches of the camera: the observational approach and the interactional approach. I will give further details on the 
interactional camera approach on the part reserved to interactions.

First of all, I as the main camera man of the team wanted to experience the observational method which consists on turning on the computer and filming until the informants are not more aware of its presence. By so doing, I tried to catch the actions of the students, teachers and attendants at the symposium in a natural way.

This method was developed by Mead and Bateson in 1942 during their two-year field work in Bali (Indonesia). During that period, while Bateson took photos and filmed, Mead interviewed, chatted and took notes. They ended up with 25,000 photos and 7000 meters of film. As a result, they wrote Balinese character: a photographic analysis. This book presented how from images and films, it is possible to learn and know many things about a culture in spite of its remoteness from the viewers. According to Mead and Bateson (1974), visual ethnography can be defined as-the study of man based on what is offered to vision alone and grasped through non-verbal tools of investigation. Hence, the camera was to be considered as a sort of secret weapon; invisible, omniscient and omnipotent, capable of witnessing the whole of an event As Mead and Bateson (1974) recommended, I tried to keep the camera on a tripod in the background and simply let it film continuously so that people forgot it was there. This was done notably at the workshops during the seminar as well as during some lectures on conflict mediation we attended.

\subsection{Approaching My Informants from an African Perspective}

Besides the theoretical assumptions that influenced my guise during my contact with my informants, there was also my African background. Instead of repressing it and pretend to reach an objective anthropological knowledge, reflexivity encourages me to identify my subjectivity, my personal convictions about my informants and to show how this contributed to the construction of the knowledge.

In fact, this method focuses on the awareness of the researcher and the effect they may be having on the research. It involves a constant awareness and assessment of the researcher's own contribution to and influence on the researcher's subjects and their findings. This principle was perhaps first thought of by William Thomas, as the "Thomas Theorem”. Reflexivity, in Turner's sense (cited by Myerhoff et al. 1982), reflexivity refers to moments in which social actors become conscious of and can reflect upon social life in ritual and other cultural performances which are "reflexive in the sense of showing ourselves ourselves ... arousing consciousness of ourselves as we see ourselves" (1982: 105).

Hence, reflexivity requires a researcher's awareness of the effects that he/she might have on the information that is being recorded. Fieldwork in cultural anthropology is a reflexive experience. Anthropologists must constantly be aware that the information they are gathering may be skewed by their ethical opinions, or political standings. Even an anthropologist's presence in that cul- 
ture can affect the results they receive. Reflexive fieldwork must retain a respect for detailed, accurate information gathering, but it also pays precise attention to the ethical and political context of research, the background of the researchers, and the full cooperation of informants. Ethnographers have come to realize that the dependability of their knowledge of other cultures depends on clear recognition of the ethical and political aspects of fieldwork, and the acknowledgment of how these have created this knowledge. Information gathering that is involved with reflective fieldwork must be detailed and accurate. In our everyday lives reflexivity is needed in order to better understand other cultures and therefore better understand ourselves. It is important to put one's own opinions and ways of life aside so one can open one's mind to see how others live.

In my case, coming from Africa, my attention was constantly attracted by the beauty of the environment. Since I was the one filming, and my classmate who was a Norwegian used to carry out interviews given that our informants sometimes preferred to speak in Norwegian, I would concentrate long shots on the building, on the walls and the classrooms. In fact, since my arrival in Norway in August 2013 (which is my first destination in Europe), the Breivang high school was the first secondary school where I had been. I was impressed and surprised to see how nice and clean it was. I used to refer to our high schools back home full of dirt and outnumbered with many students. I remember my first year in secondary school when in a small classroom of $100 \mathrm{~m}^{2}$, we were almost $200 \mathrm{stu}-$ dents. There weren't enough seats for every student so some were obliged to sit on stones.

I was so impressed that I told my classmate: In my country, even the nicest university has not reached this level of modernity! She was also amazed of my assertion because there was nothing special for her. It took me time to realize that our goal was not to film the buildings but mostly people.

At the level of interpersonal behavior, I was surprised by the fact that most of the students were indifferent to the camera and to our presence. We were not taken as special strangers. From my African experience, I know that when youths see a camera, rush towards it in order to be filmed and seen on the TV. In such an event, even the members of the administration would like to welcome the camera in order to be filmed. But till the end of the fieldwork, I didn't meet any member of the administration. It seemed that everything was ordinary for them. That is why we had to negotiate to find a contact person from whom we could start. Furthermore, I was astonished by the relax way students could relate to their lecturers. Naming them with their first names as if they were colleagues. In Africa, students are not allowed to call teachers with their first names; they must rather use titles like Sir, Madam, Doctor, Professor or Director.

But at Breivang, the atmosphere was rather relaxing: students and teachers could sit around a table and discuss. The lectures were not unidirectional from the teachers to the students but inclusive where the teacher becomes just as a moderator among the students. 


\section{From Observational to Shared Anthropology: The Interactions between Me, My Classmates, My Informants and the Camera}

Beyond the observational approach, I used interactions in order to gain access to the emic point of view.

\subsection{The Interaction between Me and My Teammate}

The mini fieldwork in Breivang high school was a nice opportunity to experience the realities of a team work in social sciences. My relationships with my classmate were sometimes controversial sometimes complimentary but both contributed considerably to the enrichment of the scientific knowledge we gathered.

For example, while from my African perspective I attention was easily caught by the aspects of modernity in the high school, my classmate who recall me that our mission is to work on the impact of school mediation in the school but not to observe the walls and the buildings. These remarks were useful to me because they helped me to focus my attention mostly on human interactions.

On the other hand, I think I was helpful to my teammate by giving reminding her the importance of focusing sometimes on the environment. In fact, one of the visual ethnography techniques we were taught was to think of the fieldwork not only in term of the thesis writing, but also in term of the continuity and the beauty of a documentary film that can be appreciated by the anthropologist audience as well as the non-anthropologist audience.

But at times, some remarks were not taken in the right way and would let us end in some disagreements with my classmate. But all these experiences were useful because they enabled me to learn how complex is a team work. In order to succeed it one need to be patient and constructive.

\subsection{The Interactions with My Informants}

The communication process with our informants was also an interesting source of knowledge production. As I previously wrote, I was impressed by the relax manner the teachers and the students were behaving both in classrooms and in the school yard.

Though I had just arrived in Tromsø, I learnt many Norwegian words during the fieldwork since most of my informants used to speak to me in Norwegian. When I wouldn't understand a word, I would ask them its meaning in English. They were enthusiast to tell me its meaning. Hence, I ended up knowing the basics of Norwegian like greetings: Hei! (Hi!), Jeg heter ... (My name is ...) One of the sentences that repeatedly came was: Hvor kommer du fra? (Where do you come from?) I was happy to see how interested they were in my presence among them. In order to establish a dialogue, I would ask them also whether they knew something about Africa. Whatever is the answer, it gives me an alibi to start conversation which would sometimes delve into school mediation. By being open and replying in Norwegian I easily became familiar with some informants like Sylvi and Håkon. 
Learning the language of the native is one of the renowned strategies used by many classic and modern anthropologists in order to grasp the realities from inside. For instance, Lisbeth Holtedahl learned the Fulfulde, a local language spoken in Northern Cameroon, Niger, Mali and Senegal. Thanks to this language, Lisbet (2000) could reach both the ordinary people or the rich like the very rich Fulani entrepreneur Al Hadji Abbo Ousmanou. Though I didn't reach that level of language, the mini fieldwork in Breivang high school enabled me to understand the importance of the native language for an anthropologist.

\subsection{The Camera as an Actor}

Conscious of the fact that it is unrealistic to think that people can forget the presence of the camera and that from the framing to the choice of scenes and shots the researcher is selective, I have used the interactional camera approach. Contrary to Mead's approach previously stated, which treated the subject as a lab animal that one observes from behind a camera lens, I tried to place the camera at the center of some of our interviews.

For instance, when we asked Håkon whether we could film his home in order to better relate our filmic story, he firstly refused arguing that his home was not nice to see. In fact, he thought that because he wanted to show a perfect image of himself not only to us but also to the audience who could lately watch the film. After having arranged his house, he finally accepted to have it filmed. So, because of the presence of the camera, the behavior of our informant changed. This shows how the camera can considerably influence the behavior of informants. I early understood why Bjørn and Holtedahl (2005) spoke of the third audience in addition to the interviewer and the interviewee who are physically absent but psychologically perceptible in the mind of the actors in a social arena.

Likewise, Jean Rouch considers the presence of the camera as an asset. Rather than giving people the impression of being filmed unwillingly and without having a real understanding of the way filming is being carried out, the camera should be placed at the center of the interaction. The purpose of this is not to question the way the camera changes behavior, but to film interaction in the presence of the camera, while remaining conscious of the distortion it brings (Young, 1974). For Young, The Camera should not be kept in the background or project a distant panorama of human objects, but should be close to the action and be inserted into the heart of the event so as to make it more intimate. The film and the fimmaker should be as close to the reality as direct observation. This approach lays the foundation of what will be termed as shared anthropology.

\subsection{The Transformations of the Knowledge in the Editing}

Besides the filming period, the rough-cut screening period is another turning point on this mini fieldwork film Mc Dougald (1974). There were particularly three phases that brought transformations to our initial hypothesis. 
Firstly, in the editing room, we realized that we had more interviews with students than with educators like Håkon and Sylvi. So instead of taking one of them as our main informant as we previously planned, we were obliged to shift our attention and focus on the students. This inflexion seemed very interesting for the further development of our project given that if Restorative Justice is taught it is mostly to educate students on the culture of forgiveness and peace but not the educators who are already mature.

Secondly, our department organized some rough cuts screening sessions prior to the finalization of our film. During those sessions we got some constructive critiques and remark which were all useful to the knowledge construction. In fact, after the rough-cut screening some viewers said they were confused on the main focus of the introduction: Hakkon's arrival or the students' arrival. This remark reflected clearly the dilemma we had between Håkon or one of the students as our main informant during the filming process.

Another remark made to us during the rough-cut screening that deserves to be raised here is that there were too many cut a way. In fact, given that we had too many interviews, we forgot to remember the filmic and event progression. We had in total 7 interviews: two with Håkon, two with two different groups of four girls, one with Silvi, one with a young girl and one with a young boy. Though at the end we didn't include the last two interviews as well as the one we had with Håkon in his home, we still remained with too many interviews for a two-week film. To -hide this abundance of interviews, we tried to multiply cut a way in between and during interviews. But as it was pointed out, we learnt that the excess of cut a way sometimes diverts from the topic.

Thirdly, we invited our informants to come and watch the film in the studio before the final version. Though they approved totally what we did, we were edified to see their reactions after some shots. One of the students said that she didn't remember having spoken like that though she didn't disagree on the film being shown. This made me understand that Mead's observational approach has still its relevance: to catch the informant in his/her natural being.

\section{Conclusion}

The two-week fieldwork my classmate and I had in Breivang high school was a tremendous opportunity for me to experience the applicability of the theories learnt in classrooms and the realities of fieldwork. It enabled me to understand the strengths and the weaknesses of my personal assumptions and the necessity to be open to learn from the other actors. The data has been successively transformed under the conjugation of different subjectivities constituted of all the actors on the field via the mediation of the camera.

Reflexivity requires a researcher's awareness of the effects that he/she might have on the information that is being recorded. Fieldwork in cultural anthropology is a reflexive experience. Anthropologists must constantly be aware that the information they are gathering may be skewed by their ethical opinions, or 
political standings. Even an anthropologist's presence in that culture can affect the results they receive. Reflexive fieldwork must retain a respect for detailed, accurate information gathering, but it also pays precise attention to the ethical and political context of research, the background of the researchers, and the full cooperation of informants. I understand that an anthropological knowledge is obtained by the contributions of the researcher, the informants and the camera. I also understood the importance of the learning the native's language in order to get closer to his/her realities.

\section{Conflicts of Interest}

The author declares no conflicts of interest regarding the publication of this paper.

\section{References}

Augé, M. (1994). Pour une anthropologie des mondes contemporains. Paris: Flammarion.

Bjørn, A., \& Holtedahl, L. (2005). Visualizing Situatedness. The Role of the Audience/Reader in Knowledge Production. In E. Engelstadt, \& S. Gerrard (Eds.), Challenging Situatedness Culture and Production of Knowledge (pp. 67-83). Delft: Eburon Press.

Boaz, F. (1989). A Franz Boas Reader: The Shaping of American Anthropology. Chicago, IL: University of Chicago Press.

Dion, C. (2007). The Contribution made by Visual Ethnography to the Study of Consumption Behavior. Recherche et Application en Marketing, 22, 61-78. https://doi.org/10.1177/205157070702200104

Hockings, P. (1974). The History of Ethnographic Film. In Principles of Visual Anthropology (pp. 13-43). Berlin: Mouton de Guyter.

Holtedahl, L. (1993). Communication Problems in Social Research. In P. Crawford (Ed.), The Nordic Eye. Proceedings from NAFA. Højbjerg: Intervention Press.

Levi-Strauss, C. (1976). Structural Anthropology(Volume II). New York: Basic Books, Inc. https://doi.org/10.2307/3032172

Lisbet, H. (2010). Up as a Rabbit, Down as a Lion: Socio-Economic Determinants of New Idioms of Power-Visual Case Stories from Urban Adamaoua, Cameroon. Africa Development, Codesria, 35, 117-175. https://doi.org/10.4314/ad.v35i1-2.70202

Manilowski, B. (1989). Argonauts of the Western Pacific: An Account of Native Enterprise and Adventure in the Archipelagoes of Melanesian New Guinea. Studies in Economics and Political Science, No. 65, London: Routledge and Kegan Paul.

Mead, M., \& Bateson, G. (1974). Balineese Character: A Photographic Analysis. New York: Academy of Science.

Myerhoff, B., \& Jay, R. (1982). The Cracked Mirror: Reflexive Perspectives in Anthropology. Philadelphia, PA: University of Pennsylvania Press.

Rouch, J. (2003). Cine-Ethnography, Visible Evidence (Vol. 13). Minneapolis, MN: University of Minnesota Press.

Ruby, J. (2000). Picturing Culture: Explorations of Film and Anthropology. Chicago, IL: The University of Chicago Press.

Young (1974). Beyond Observational Cinema. In Principles of Visual Anthropology (pp. 117-132). Berlin: Mouton de Guyter. 